\title{
Poultry Diseases Warning System using Dempster- Shafer Theory and Web Mapping
}

\author{
Andino Maseleno \\ Computer Science Program \\ Faculty of Science, Universiti Brunei Darussalam \\ Jalan Tungku Link, Gadong BE 1410, Brunei Darussalam
}

\author{
Md. Mahmud Hasan \\ Computer Science Program \\ Faculty of Science, Universiti Brunei Darussalam \\ Jalan Tungku Link, Gadong BE 1410, Brunei Darussalam
}

\begin{abstract}
In this research, the researcher built a Web Mapping and Dempster-Shafer theory as an early warning system of poultry diseases. Early warning is the provision of timely and effective information, through identified institutions, that allows individuals exposed to a hazard to take action to avoid or reduce their risk and prepare for effective response. In this paper as an example we use five symptoms as major symptoms which include depression, combs, wattle, bluish face region, swollen face region, narrowness of eyes, and balance disorders. Research location is in the Lampung Province, South Sumatera. The researcher's reason to choose Lampung Province in South Sumatera on the basis that has a high poultry population. Our approach uses Dempster-Shafer theory to combine beliefs in certain hypotheses under conditions of uncertainty and ignorance, and allows quantitative measurement of the belief and plausibility in our identification result. Web Mapping is also used for displaying maps on a screen to visualize the result of the identification process. The result reveal that Poultry Diseases Warning System has successfully identified the existence of poultry diseases and the maps can be displayed as the visualization.
\end{abstract}

Keywords-poultry diseases; early warning system; Dempster-Shafer theory, web mapping

\section{INTRODUCTION}

The demand for chicken meat has been increasing because it has become cheaper relative to other meats The term poultry refers to domesticated fowl raised for meat or eggs. The poultry industry is dominated by the chicken companies, development of poultry population and poultry industry is very rapidly threatened by the presence of poultry disease. Disease is defined as a departure from health, and includes any condition that impairs normal body functions. Disease results from a combination of indirect causes that reduce resistance or predispose an animal to catching a disease, as well as the direct causes that produce the disease.

Avian influenza virus, which has been limited to poultry, now has spread to migrating birds and has emerged in mammals and among the human population. It presents a distinct threat of a pandemic for which the World Health Organization and other organizations are making preparations [1]. In 2005, the World Health Assembly urged its Member States to develop national preparedness plans for pandemic influenza [2]. Developing countries face particular planning and other challenges with pandemic preparedness as there may be a higher death rate in developing countries compared with more developed countries [3].

In this research, we were using chicken as research object because chicken population has grown very fast in Lampung Province at 2009, native chicken population around $11,234,890$, broiler population around 15,879,617, layer population around 3,327,847. Lampung Province has been divided into 10 regencies, 204 districts and 2279 villages with area of 3,528,835 hectare [4].

To overcome poultry diseases required an early warning system of poultry diseases. International Strategy for Disaster Reduction (ISDR) defines early warning as the provision of timely and effective information, through identified institutions, that allows individuals exposed to a hazard to take action to avoid or reduce their risk and prepare for effective response [5]..

The remainder is organized as follows. The Web mapping is briefly reviewed in Section 2. Section 3 details the proposed Dempster-Shafer Theory. Architecture of Poultry Diseases Warning System is detailed in Section 4. The experimental results are presented in Section 5, and final remarks are concluded in Section 6.

\section{WEB MAPPING}

Web mapping is the process of designing, implementing, generating and delivering maps on the World Wide Web and its product. While web mapping primarily deals with technological issues, web cartography additionally studies theoretic aspects: the use of web maps, the evaluation and optimization of techniques and workflows, the usability of web maps, social aspects, and more. Web Geographic Information System (GIS) is similar to web mapping but with an emphasis on analysis, processing of project specific geo data and exploratory aspects [6].

The web mapping server is the engine behind the maps [7]. The mapping server or web mapping program needs to be configured to communicate between the web server and assemble data layers into an appropriate image. A map is not possible without some sort of mapping information for display. Mapping data is often referred to as spatial or geospatial data and can be used in an array of desktop mapping programs or web mapping servers. Mapping data in the Poultry Diseases 
Warning System uses spatial and non-spatial data in ArcView format. Table 1 shows the data mapping.

TABLE I. DATA MAPPING

\begin{tabular}{|c|c|c|}
\hline Data Type & Data Name & Description \\
\hline Spatial & $\begin{array}{c}\text { Province } \\
\text { Regencies } \\
\text { District } \\
\text { Desa }\end{array}$ & $\begin{array}{c}\text { Spatial Data digitized on } \\
\text { screen with ArcView }\end{array}$ \\
\hline Non-Spatial & $\begin{array}{c}\text { Province Table } \\
\text { Regency Table } \\
\text { District Table } \\
\text { Village Table }\end{array}$ & $\begin{array}{c}\text { Data tabulated into flat table } \\
\text { of which follow data spatial }\end{array}$ \\
& \\
& & \\
&
\end{tabular}

\section{DEMPSTER-SHAFER THEORY}

The Dempster-Shafer theory was first introduced by Dempster [8] and then extended by shafer [9], but the kind of reasoning the theory uses can be found as far back as the seventeenth century. This theory is actually an extension to classic probabilistic uncertainty modeling. Whereas the Bayesian theory requires probabilities for each question of interest, belief functions allow us to base degrees of belief for on question on probabilities for a related question. The Dempster-Shafer (D-S) theory or the theory of belief functions is a mathematical theory of evidence which can be interpreted as a generalization of probability theory in which the elements of the sample space to which nonzero probability mass is attributed are not single points but sets. The sets that get nonzero mass are called focal elements. The sum of these probability masses is one, however, the basic difference between D-S theory and traditional probability theory is that the focal elements of a Dempster-Shafer structure may overlap one another. The D-S theory also provides methods to represent and combine weights of evidence.

$\mathrm{m}: 2^{\Theta} \rightarrow[0,1]$ is called a basic probability assignment (bpa) over $\Theta$ if it satisfies

$\mathrm{m}(\varnothing)=0$ and

$$
\sum_{S \subset \theta} m(S)=1
$$

From the basic probability assignment, the upper and lower bounds of an interval can be defined. This interval contains the precise probability of a set of interest and is bounded by two nonadditive continuous measures called Belief (Bel) and Plausibility $(\mathrm{Pl})$. The lower bound for a set $A, \operatorname{Bel}(A)$ is defined as the sum of all the basic probability assignments of the proper subsets $(B)$ of the set of interest $(A)(\mathrm{B} \subseteq \mathrm{A})$. Formally, for all sets $A$ that are elements of the power set, A $\in 2^{\Theta}$

$$
\sum_{s \subset \boldsymbol{\theta}} m(S)=1
$$

A function PL: $2^{\Theta} \rightarrow[0,1]$ is called a plausibility function satisfying

$$
\sum_{B \cap A \neq 0} m(B)
$$

The plausibility represents the upper bound for a set $A$, and is the sum of all the basic probability assignments of the sets
$(B)$ that intersect the set of interest $(A)(B \cap A \neq \varphi)$. The precise probability $P(A)$ of an event (in the classical sense) lies within the lower and upper bounds of Belief and Plausibility, respectively:

$$
\operatorname{Bel}(A) \leq P(A) \leq P L(A)
$$

In terms of previous work using Dempster-Shafer theory to estimate stand regeneration maps [10], [11]. Actually, according to researchers knowledge, Dempster-Shafer theory of evidence has never been used for built an early warning system of poultry diseases fusion with Web Mapping.

The result is that Poultry Diseases Warning System successfully identifying disease and displaying location to visualize the result of identification process. Symptoms:

1. Depression

2. Combs, wattle, bluish face region

3. Swollen face region

4. Narrowness of eyes

5. Balance disorder

\section{A. Symptom 1}

Depression is a symptom of Avian Influenza (AI), Newcastle Disease (ND), Fowl Cholera (FC), Infectious Bronchitis respiratory form (IBRespi), Infectious Bronchitis reproduction form (IBRepro), and Swollen Head Syndrome (SHS). The measures of uncertainty, taken collectively are known in Dempster Shafer Theory terminology as a "basic probability assignment" (bpa). Hence we have a bpa, say $\mathrm{m}_{1}$ of 0.7 given to the focal element $\{\mathrm{AI}, \mathrm{ND}, \mathrm{FC}, \mathrm{IBRespi}$, IBRepro, SHS $\}$ in example, $\mathrm{m}_{1}(\{\mathrm{AI}, \mathrm{ND}, \mathrm{FC}$, IBRespi, IBRepro, SHS $\})=0.7$, since we know nothing about the remaining probability it is allocated to the whole of the frame of the discernment in example, $\mathrm{m}_{1}(\{\mathrm{AI}, \mathrm{ND}, \mathrm{FC}, \mathrm{IBRespi}$, IBRepro, SHS $\})=0.3$, so:

$\mathrm{m}_{1}\{$ AI, ND, FC, IBRespi, IBRepro, SHS $\}=0.7$

$\mathrm{m}_{1}\{\Theta\}=1-0.7=0.3$

\section{B. Symptom 2}

Combs, wattle, bluish face region are symptoms of Avian Influenza with a bpa of 0.9 , so that:

$\mathrm{m}_{2}\{\mathrm{AI}\}=0.9$

$\mathrm{m}_{2}\{\Theta\}=1-0.9=0.1$

With the symptoms comb, wattle, bluish face region then required to calculate the new bpa values for some combinations $\left(\mathrm{m}_{3}\right)$. Table 2 shows combination rules for $\mathrm{m}_{3}$.

TABLE II. COMBINATION OF SYMPTOM 1 AND SYMPTOM 2

\begin{tabular}{|l|l|l|l|l|l|}
\hline \multicolumn{2}{|c|}{} & $\{\mathrm{AI}\}$ & 0.9 & $\Theta$ & 0.1 \\
\hline $\begin{array}{l}\text { \{AI, ND, FC, } \\
\text { IBRespi, IBRepro, } \\
\text { SHS }\}\end{array}$ & 0.7 & $\{\mathrm{AI}\}$ & 0.63 & $\begin{array}{l}\{\mathrm{AI}, \mathrm{ND}, \mathrm{FC}, \\
\text { IBRespi, BRepro, } \\
\text { SHS }\}\end{array}$ & 0.07 \\
\hline$\Theta$ & $\mathbf{0 . 3}$ & $\{\mathrm{AI}\}$ & 0.27 & $\Theta$ & 0.03 \\
\hline
\end{tabular}

We then calculate the combined of equation (5) and equation (6) as shown in the equation (7).

$\mathrm{m}_{3}(\mathrm{AI})=\frac{0.63+0.27}{1-0}=0.9$ 
$\mathrm{m}_{3}(\mathrm{AI}, \mathrm{ND}, \mathrm{FC}, \mathrm{IBRespi}$, IBRepro, SHS $)=\frac{0.07}{1-0}=0.07$

$\mathrm{m}_{3}(\Theta)=\frac{0.03}{1-0}=0.03$

\section{Symptom 3}

Swollen face region is a symptom of Avian Influenza, Newcastle Disease, Fowl Cholera with a bpa of 0.83 , so that $\mathrm{m}_{4}\{\mathrm{AI}, \mathrm{ND}, \mathrm{FC}\}=0.83$

$\mathrm{m}_{4}(\Theta)=1-0.83=0.17$

With the symptom swollen face region then required to calculate the new bpa values for each subset. Table 3 shows combination rules for $\mathrm{m}_{5}$.

TABLE III. COMBINATION OF SYMPTOM 1, SYMPTOM 2, AND SYMPTOM 3

\begin{tabular}{|l|l|l|l|l|l|}
\hline \multicolumn{2}{|l|}{} & $\{$ AI, ND, FC $\}$ & $\mathbf{0 . 8 3}$ & $\boldsymbol{\Theta}$ & $\mathbf{0 . 1 7}$ \\
\hline$\{\mathrm{AI}\}$ & $\mathbf{0 . 9}$ & $\{\mathrm{AI}\}$ & 0.747 & $\{\mathrm{AI}\}$ & 0.153 \\
\hline $\begin{array}{l}\{\mathrm{AI}, \quad \text { ND, FC, } \\
\text { IBRespi, IBRepro, } \\
\text { SHS }\}\end{array}$ & $\mathbf{0 . 0 7}$ & $\{\mathrm{AI}, \mathrm{ND}, \mathrm{FC}\}$ & 0.0581 & $\begin{array}{l}\{\mathrm{AI}, \mathrm{ND}, \mathrm{FC}, \\
\text { IBRespi, } \\
\text { IBRepro, SHS }\}\end{array}$ & 0.0119 \\
\hline $\boldsymbol{\Theta}$ & $\mathbf{0 . 0 3}$ & $\{$ AI, ND, FC $\}$ & 0.0249 & $\boldsymbol{\Theta}$ & 0.0051 \\
\hline
\end{tabular}

We then calculate the combined of equation (7) and equation (8) as shown in the equation (9).

$\mathrm{m}_{5}(\mathrm{AI})=\frac{0.747+0.153}{1-0}=0.9$

$\mathrm{m}_{5}(\mathrm{AI}, \mathrm{ND}, \mathrm{FC})=\frac{0.0581+0.0249}{1-0}=0.083$

$\mathrm{m}_{5}(\mathrm{AI}, \mathrm{ND}, \mathrm{FC}, \mathrm{IBRespi}, \mathrm{IBRepro}, \mathrm{SHS})=\frac{0.0119}{1-0}=0.0119$

$\mathrm{m}_{5}(\Theta)=\frac{0.0051}{1-0}=0.0051$

\section{Symptom 4}

Narrowness of eyes is a symptom of Swollen Head Syndrome with a bpa of 0.9 , so that:

$\mathrm{m}_{6}(\mathrm{SHS})=0.9$

$\mathrm{m}_{6}(\Theta)=1-0.9=0.1$

With the symptom narrowness of eyes then required to calculate the new bpa values for each subset with bpa $\mathrm{m}_{7}$. Table 4 shows combination rules for $\mathrm{m}_{7}$.

\begin{tabular}{|l|l|l|l|l|l|}
\hline & & $\{$ SHS $\}$ & $\mathbf{0 . 9}$ & $\boldsymbol{\Theta}$ & $\mathbf{0 . 1}$ \\
\hline$\{$ AI $\}$ & $\mathbf{0 . 9}$ & $\Theta$ & 0.81 & $\{$ AI $\}$ & 0.09 \\
\hline$\{$ AI, ND, FC $\}$ & $\mathbf{0 . 0 8 3}$ & $\Theta$ & 0.0747 & $\{$ AI, ND, FC $\}$ & 0.0083 \\
\hline $\begin{array}{l}\{\text { AI, ND, FC, } \\
\text { IBRespi, IBRepro, } \\
\text { SHS }\}\end{array}$ & $\mathbf{0 . 0 1 1 9}$ & $\{$ SHS $\}$ & 0.01071 & $\begin{array}{l}\{\text { AI, ND, FC, } \\
\text { IBRespi, IBRepro, } \\
\text { SHS }\end{array}$ & 0.00119 \\
\hline $\mathbf{\Theta}$ & $\mathbf{0 . 0 0 5 1}$ & $\{$ SHS $\}$ & 0.00459 & $\boldsymbol{\Theta}$ & 0.00051 \\
\hline
\end{tabular}

TABLE IV. COMBINATION OF SYMPTOM 1, SYMPTOM 2, SYMPTOM 3, AND SYMPTOM 4
We then calculate the combined of equation (9) and equation (10) as shown in the equation (11).

$\mathrm{m}_{7}(\mathrm{SHS})=\frac{0.01071+0.00459}{1-(0.81+0.0747)}=0.13270$

$\mathrm{m}_{7}(\mathrm{AI})=\frac{0.09}{1-(0.81+0.0747)}=0.78057$

$\mathrm{m}_{7}(\mathrm{AI}, \mathrm{ND}, \mathrm{FC})=\frac{0.0083}{1-(0.81+0.0747)}=0.07199$

$\mathrm{m}_{7}(\mathrm{AI}, \mathrm{ND}, \mathrm{FC}$, IBRespi, IBRepro, SHS $)=$

$\frac{0.00119}{1-(0.81+0.0747)}=0.01032$

$\mathrm{m}_{7}(\Theta)=\frac{0.00051}{1-(0.81+0.0747)}=0.00442$

\section{E. Symptom 5}

Balance disorders is a symptom of Newcastle Diseases and Swollen Head Syndrome with a bpa of 0.6, so that:

$\mathrm{m}_{8}\{\mathrm{ND}, \mathrm{SHS}\}=0.6$

$\mathrm{m}_{8}\{\Theta\}=1-0.6=0.4$

With the symptom balance disorders will be required to calculate the new bpa values for each subset with $m_{9}$ bpa. Table 5 shows combination rules for $\mathrm{m}_{9}$.

TABLE V. COMBINATION OF SYMPTOM 1, SYMPTOM 2, SYMPTOM 3, SYMPTOM 4, AND SYMPTOM 5

\begin{tabular}{|c|c|c|c|c|c|}
\hline & & $\{\mathrm{ND}, \mathrm{SHS}\}$ & 0.6 & $\boldsymbol{\Theta}$ & 0.4 \\
\hline$\{$ SHS $\}$ & 0.13270 & $\{\mathrm{SHS}\}$ & 0.07962 & $\{\mathrm{SHS}\}$ & 0.05308 \\
\hline$\{\mathbf{A I}\}$ & 0.78057 & $\boldsymbol{\Theta}$ & 0.46834 & $\{\mathrm{AI}\}$ & 0.31222 \\
\hline$\{\mathrm{AI}, \mathrm{ND}, \mathrm{FC}\}$ & 0.07199 & $\{\mathrm{ND}\}$ & 0.04319 & $\begin{array}{l}\{\mathrm{AI}, \mathrm{ND}, \\
\mathrm{FC}\}\end{array}$ & 0.02880 \\
\hline $\begin{array}{l}\text { \{AI, ND, FC, } \\
\text { IBRespi, } \\
\text { IBRepro, SHS }\}\end{array}$ & 0.01032 & $\{\mathrm{ND}, \mathrm{SHS}\}$ & 0.00619 & $\begin{array}{l}\text { \{AI, ND, } \\
\text { FC, } \\
\text { IBRespi, } \\
\text { IBRepro, } \\
\text { SHS }\}\end{array}$ & 0.00413 \\
\hline $\boldsymbol{\Theta}$ & 0.00442 & $\{\mathrm{ND}, \mathrm{SHS}\}$ & 0.00265 & $\boldsymbol{\Theta}$ & 0.00177 \\
\hline
\end{tabular}

We then calculate the combined of equation (11) and equation (12) as shown in the equation (13).

$\mathrm{m}_{9}(\mathrm{SHS})=\frac{0.07962+0.05308}{1-0.46834}=0.24960$

$\mathrm{m}_{9}(\mathrm{AI})=\frac{0.31222}{1-0.46834}=0.58725$

$\mathrm{m}_{9}(\mathrm{ND})=\frac{0.04319}{1-0.46834}=0.08124$

$\mathrm{m}_{9}(\mathrm{ND}, \mathrm{SHS})=\frac{0.00619+0.00265}{1-0.46834}=0.01663$

$\mathrm{m}_{9}(\mathrm{AI}, \mathrm{ND}, \mathrm{FC})=\frac{0.02880}{1-0.46834}=0.05417$

$\mathrm{m}_{9}(\mathrm{AI}, \mathrm{ND}, \mathrm{FC}, \mathrm{IBRespi}, \mathrm{IBRepro}, \mathrm{SHS})=$ $\frac{0.00413}{1-0.46834}=0.00777$ 
$\mathrm{m}_{9}$

$$
=
$$$$
\frac{0.000232}{1-0.061038}=0.00025
$$

The highest bpa value is the $m_{9}(\mathrm{AI})$ that is equal to 0.58725 which means the possibility of a temporary diseases with symptoms of depression, comb, wattle, bluish face region, swollen region face, narrowness of eyes, and balance disorders is the Avian influenza (H5N1).

\section{POULTRY DiSEASES WARNING SYSTEM}

Figure 1 shows architecture of Poultry Diseases Warning System which is fusion between the Dempster-Shafer theory and Web Map Application.

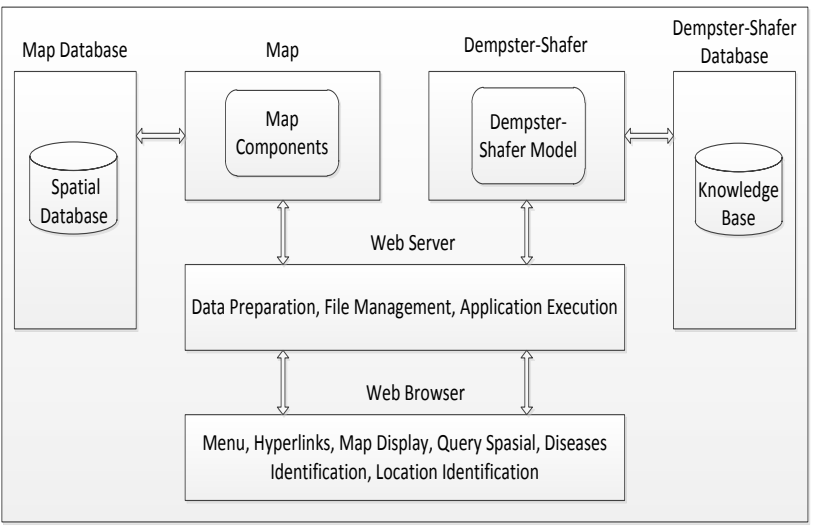

Figure 1. Architecture of Poultry Diseases Warning System

The development of Poultry Diseases Warning System to begin with:

1. Preparation which includes installing and setting programs.

2. Preparation of attributes data and spatial data that already exist so it can be used by the program application.

3. Database design with MySQL. At this stage the databases design regarding the depiction relationships between entities using diagram of relationships between entities (entity relationship diagrams).

4. Designing Web pages using PHP. This web page then connected to the database and spatial attributes that have been established to form a network of database.

5. Designing a Web-based applications used to access the network database that has been formed. The relationship between applications with network data base that has shaped overall applications to manage information to be displayed.

\section{IMPLEMENTATION}

Poultry Diseases Warning System is applying web mapping technology using MapServer software. Map data obtained from digitized by ArcView for creating and editing dataset. The implementation process is done after design and scope of the system have been analyzed. Writing map file using Macromedia Dreamweaver. Macromedia Dreamweaver for writing map file that later on as the main file from system configuration and layout as well. Spatial and non spatial data designed using ArcView. Each data is designed to accommodate operation at the layer level, either single layer or multi layer.

The following will be shown the working process of expert system in diagnosing a case. The consultation process begins with selecting the location and symptoms found on the list of symptoms. In the cases tested, a known symptoms are depression, comb, wattle, bluish-colored facade region, region of the face swollen, eyes narrowed and balance disorders. The consultation process can be seen in Figure 2 and Figure 3.

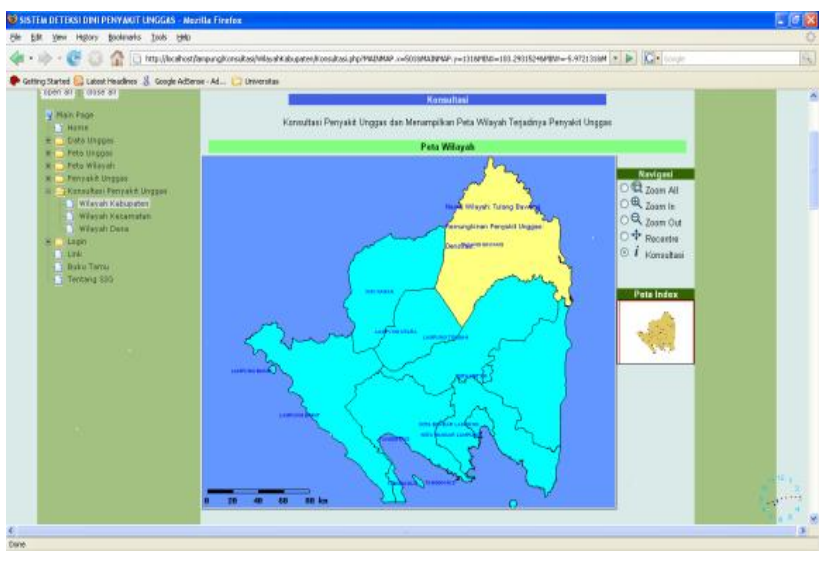

Figure 2. Selecting Region of Consultation

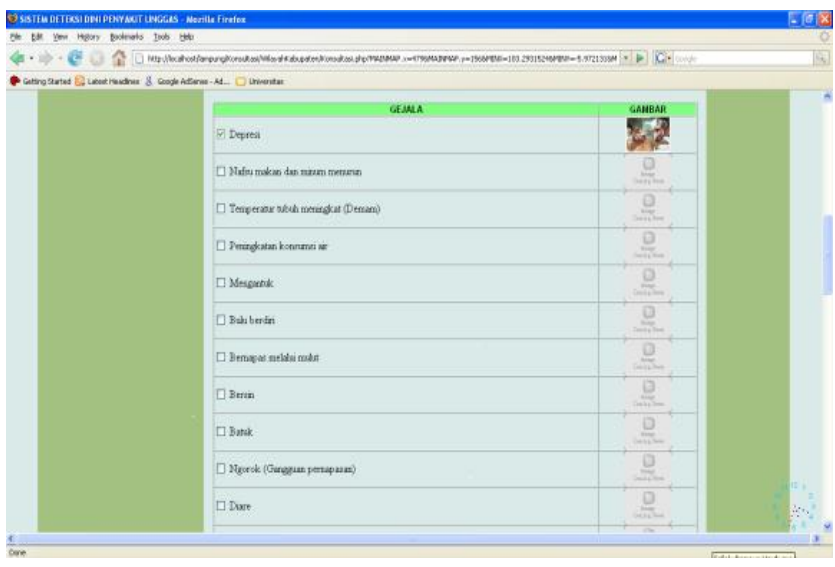

Figure 3. Symptoms Selection

In the case of depression, comb, wattle and region of the face bluish, region of the face swollen, eyes narrowed and lachrymal glands swollen. The result of consultation is avian influenza with bpa value equal to 0.587275693312 . Figure 4 and figure 5 are showed the result of consultation and the region map of consultation result. Consultation result shows that needs serious treatment because has basic probability assignment more than 0.5 . 


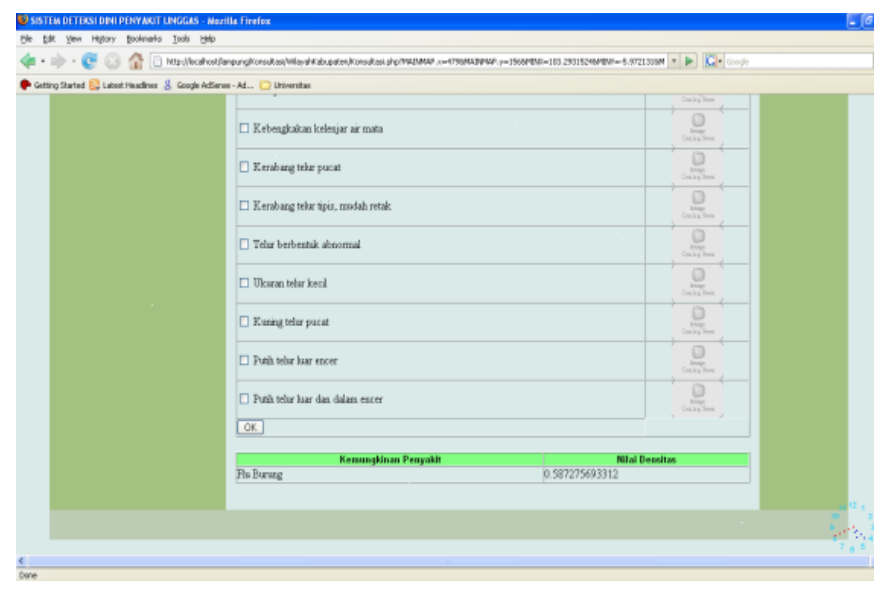

Figure 4. The Result of Consultation

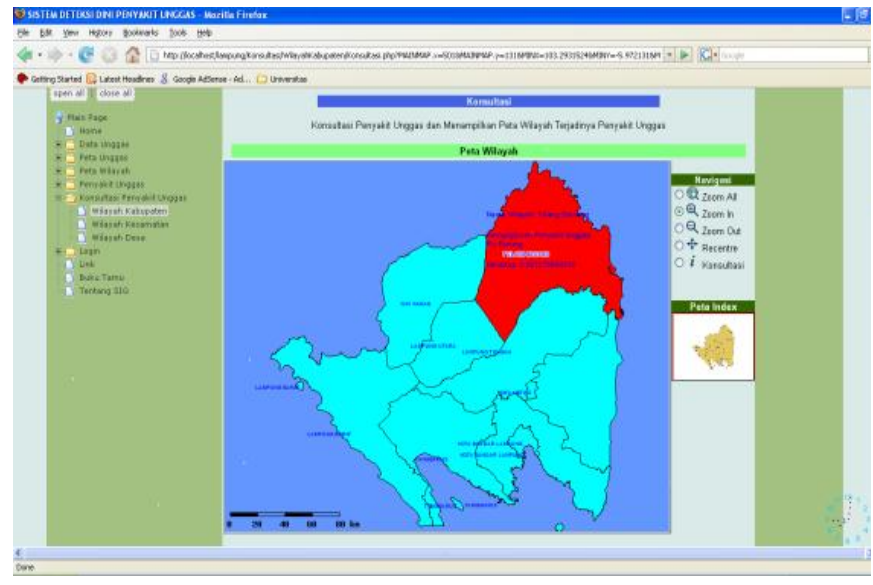

Figure 5. The Region Map of Consultation Result

\section{CONCLUSION}

In this paper as an example we use five symptoms as major symptoms which include depression, combs, wattle, bluish face region, swollen face region, narrowness of eyes, and balance disorders. The knowledge is uncertain in the collection of basic events can be directly used to draw conclusions in simple cases, however, in many cases the various events associated with each other. Knowledge base is to draw conclusions, it is derived from uncertain knowledge. Application is built to display the map of the region by the villages, districts, and regencies or municipalities. Map has been used to solve the problem of Poultry Diseases. Map can be used to integrate spatial data and descriptive data, early warning system uses map as a tool. Web Mapping and Dempster Shafer theory can be constructed as an early warning system of poultry diseases, with identified the existence of poultry diseases and the maps can be displayed as the visualization. This research can be an alternative in addition to direct consultation with doctor and to find out quickly location of poultry diseases.

\section{REFERENCES}

[1]. L. D Sims, J. Domenech, C. Benigno, S. Kahn, A. Kamata, J. Lubrouth, V. Martin, and P. Roeder, Origin and evolution of highly pathogenic H5N1 avian influenza in Asia. The Veterinary Record, August 2005, pp. $159-164$.

[2]. W. H. Assembly. Strengthening pandemic-influenza preparedness and response. Resolution, WHA58.5, 2005.

[3]. E. Azziz-Baumgartner, N. Smith, R. González-Alvarez, "National pandemic influenza preparedness planning," Influenza and Other Respiratory Viruses, July 2009, pp. $189-196$.

[4]. Anonim, Lampung in Figures, BPS - Statistics of Lampung Province, Lampung: BPS, 2010.

[5]. V. F. Grasco, Early Warning Systems: State-of-Art Analysis and Future Directions, United Nations Environment Programme, 2006.

[6]. P. Fu, and J. Sun. Web GIS: Principles and Applications, Redlands, CA: ESRI Press, 2010.

[7]. T. Mitchell, Web Mapping Illustrated, California, United States America, 2005.

[8]. A. P. Dempster, A Generalization of Bayesian inference, Journal of the Royal Statistical Society, 1968, pp. $205-$ 247.

[9]. G. Shafer, A Mathematical Theory of Evidence, Princeton University Press, New Jersey, 1976.

[10]. B. Mora, R.A. Fournier and S. Focher, "Application of evidential reasoning to improve the mapping of regenerating forest stands," International Journal of Applied Earth Observation and Geoinformation, November 2010, pp. $458-467$.

[11]. I. Bernetti, C. Ciampi, C. Fagarazzi, S. Sacchelli, "The evaluation of forest crop damages due to climate change. An application of Dempster-Shafer Method," Journal of Forest Economics, August 2011, pp. 285 - 297.

\section{AUTHORS PROFILE}

Andino Maseleno is a Ph.D. student in the Department of Computer Science, Universiti Brunei Darussalam. His research interest is in the area of artificial intelligence. He receives Graduate Research Scholarship (GRS) from Duli Yang Maha Mulia Sultan Haji Hassanal Bolkiah.

Dr. Md. Mahmud Hasan is a Senior Lecturer in the Deptartment of Computer Science, Universiti Brunei Darussalam. His research interest is in the areas of Internet Appliances, artificial intelligence and embedded system. He has 35 publications in the international and national journal/conferences/book chapters. Also hold a patent over the "Internet appliance for ECG". 